This item was submitted to Loughborough's Research Repository by the author.

Items in Figshare are protected by copyright, with all rights reserved, unless otherwise indicated.

\title{
Prevalence of diabetes and impaired glucose metabolism in younger 'at risk' UK adults: insights from the STAND programme of research
}

PLEASE CITE THE PUBLISHED VERSION

http://dx.doi.org/10.1111/dme.12173

\section{PUBLISHER}

(C) The Authors. Diabetic Medicine @ Diabetes UK

\section{VERSION}

SMUR (Submitted Manuscript Under Review)

\section{LICENCE}

CC BY-NC-ND 4.0

\section{REPOSITORY RECORD}

Wilmot, E.G., Charlotte L. Edwardson, Stuart J.H. Biddle, Trish Gorely, Joseph Henson, Kamlesh Khunti, Myra A. Nimmo, Thomas E. Yates, and Melanie J. Davies. 2019. "Prevalence of Diabetes and Impaired Glucose Metabolism in Younger 'at Risk' UK Adults: Insights from the STAND Programme of Research". figshare. https://hdl.handle.net/2134/13924. 
This item was submitted to Loughborough's Institutional Repository (https://dspace.lboro.ac.uk/) by the author and is made available under the following Creative Commons Licence conditions.

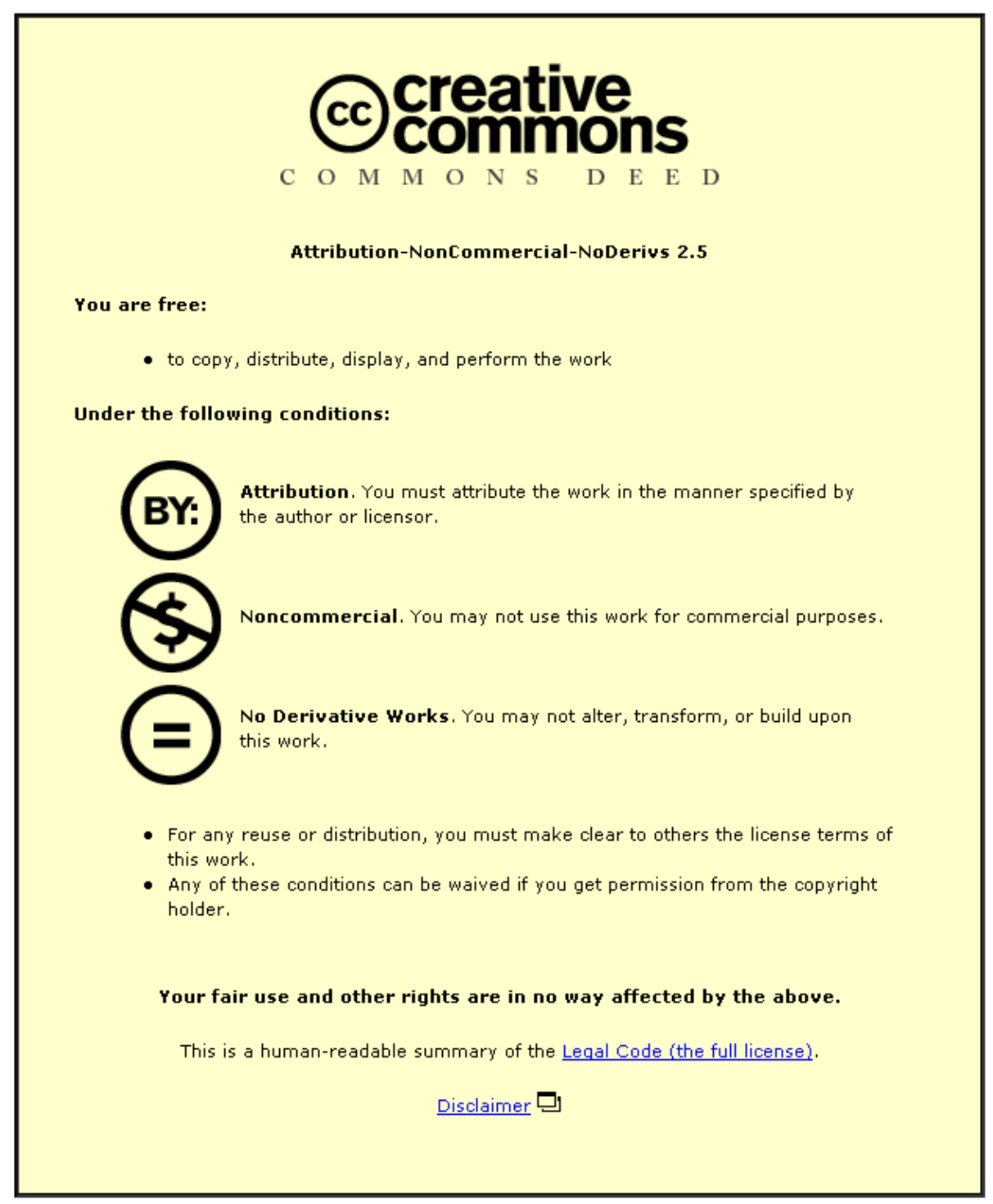

For the full text of this licence, please go to: http://creativecommons.org/licenses/by-nc-nd/2.5/ 
Prevalence of diabetes and impaired glucose metabolism in younger 'at risk' UK adults: insights from the STAND programme of research

EG Wilmot ${ }^{1,2}, \mathrm{CL}$ Edwardson ${ }^{2,3}$, SJH Biddle ${ }^{3,6}$, T Gorely $^{4}$, J Henson ${ }^{1,2,6}, \mathrm{~K}$

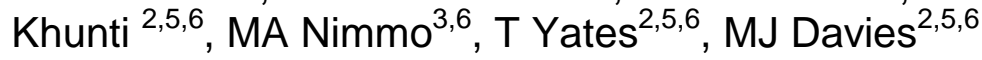

1. Department of Cardiovascular Sciences, University of Leicester, University Hospitals of Leicester NHS Trust, Leicester General Hospital, Leicester, UK

2. Leicester Diabetes Centre, University Hospitals of Leicester, UK

3. School of Sport, Exercise and Health Sciences, Loughborough University, Loughborough, UK

4. School of Sport, Stirling University, Stirling, UK

5. Diabetes Research Unit, College of Medicine, Biological Sciences and Psychology, University of Leicester, UK

6. NIHR Leicester-Loughborough Diet, Lifestyle and Physical Activity Biomedical Research Unit

Corresponding Author and guarantor:

Dr Emma Wilmot

Leicester Diabetes Centre, Leicester General Hospital, Gwendolen Road Leicester, UK LE5 4PW

Emma.Wilmot@uhl-tr.nhs.uk

Funding: The STAND study is a MRC (NPRI) funded study (Project \#91409).

Conflicts of interest: The authors have no conflicts of interest to disclose.

Novelty statements:

- NICE guidance (2012) recommends screening younger high risk individuals (aged 25-39 years) for diabetes.

- There is a lack of data on the prevalence of screen detected diabetes and impaired glucose metabolism in younger high risk UK adults.

- A cohort of younger high risk UK adults underwent an oral glucose tolerance test and HbA1c. 4.7\% were diagnosed with Type 2 DM; $18.1 \%$ had impaired glucose metabolism.

- These findings lend support to the recent NICE recommendations but will require confirmation in larger studies.

Word count: 2153 words 


\section{Abstract}

Aims: Rising rates of obesity have led to an increasing prevalence of Type 2 diabetes mellitus (Type $2 \mathrm{DM}$ ) in young people. Uncertainty exists over the utility of screening younger adults for Type 2 DM as existing datasets have focused on mature ( $>40$ years) cohorts. The aim of this study was to determine the prevalence of impaired glucose metabolism in higher risk younger adults.

Methods: Overweight (with an additional risk factor) or obese adults (18-40 years) were recruited for the Sedentary Time And Diabetes (STAND) randomised controlled trial. Measures included an oral glucose tolerance test (OGTT), HbA1c, biochemical and anthropometric data.

Results: 193 individuals (68\% female; median age 33.8 years; median BMI $33.9 \mathrm{~kg} / \mathrm{m}^{2}$ ) were recruited. $43 \%$ had a first degree family history of Type 2 DM. Previously undiagnosed Type 2 DM was present in $4.7 \%(n=9) .18 .1 \%$ $(n=35)$ had impaired glucose metabolism: $4.7 \%(n=9) \mathrm{HbA} 1 \mathrm{c} \geq 48 \mathrm{mmol} / \mathrm{mol}$ (6.5\%)); 9.3\% $(\mathrm{n}=18) \mathrm{HbA} 1 \mathrm{c} 42-46 \mathrm{mmol} / \mathrm{mol}(6.0-6.4 \%) ; 3.1 \%(\mathrm{n}=6)$ Type 2 DM on OGTT; $6.2 \%(n=12)$ isolated impaired glucose tolerance (IGT); $2.1 \%$ $(n=4)$ isolated impaired fasting glucose (IFG); $1 \%(n=2)$ both IFG and IGT. $58.5 \%(n=113)$ had dyslipidaemia, 28.0\% $(n=54)$ had hypertension, 31.1\% $(n=60)$ were vitamin $D$ deficient and $7.3 \%(n=14)$ had abnormal liver function.

Conclusions: This study identified a high prevalence of Type 2 DM and impaired glucose regulation in overweight and obese younger adults. These findings require confirmation in a larger, representative, population.

Trial registration number: Current controlled trials ISRCTN08434554, MRC project 91409. 


\section{BACKGROUND}

The appeal and availability of sedentary pursuits and energy dense foods, alongside lower levels of occupational and other physical activities, has culminated in a worldwide obesity epidemic across all age ranges. This change has driven a dramatic shift in the traditional profile of chronic disease, and we now increasingly witness the development of Type 2 DM in young people [1]. The diagnosis of Type 2 DM at a young age has profound implications for both the individual and society. It is asymptomatic in the initial stages resulting in many developing irreversible complications, often before therapy has even begun. At diagnosis, approximately half of younger adults with Type 2 DM have hyperlipidaemia and/or hypertension and one in five has microalbuminurea [2-4]. This accelerated development of micro and macrovascular complications has serious repercussions. For instance, those diagnosed $<45$ years of age have a 14 -fold increase in the risk of myocardial infarction compared to those without diabetes; and a 4-fold increase in risk compared to age matched controls who had Type 2 DM diagnosed $>45$ years [5]. In addition, early onset Type 2 DM is associated with co-morbidities such as fatty liver disease and obesity, independent risk factors for mortality $[6,7]$. Type $2 \mathrm{DM}$ in the young is a relatively recent phenomenon with limited long term follow up data but it is likely that it will culminate in excess morbidity and mortality.

The early detection and management of Type 2 DM has the potential to reduce the impact of the disease. There is a legacy effect associated with early glycaemic control and even a modest delay in the diagnosis can have negative long term implications [8]. Identifying people at high risk of Type 2 DM presents an opportunity to intervene and prevent the development of Type 2 DM. There is now a wealth of evidence from studies of older adults which illustrate that progression to Type 2 DM can be prevented or delayed with lifestyle changes which include increased physical activity and dietary modification $[9,10]$.

The importance of the early detection of Type 2 DM in younger people has been acknowledged in the recent publication by the National Institute of Clinical Excellence (NICE) guidance which recommends screening high risk individuals aged 25-39 years of age [11]. Here, high risk includes black and minority ethnic groups (BME) and people with conditions that increase the risk of Type 2 DM. However, previous diabetes screening studies have predominantly focused on older adults, overlooking the potential disease burden in those younger than 40 years and the evidence base for this recommendation is currently lacking. We therefore investigated the prevalence of impaired glucose metabolism (IGM), Type 2 DM and cardiovascular risk factors in a multi-ethnic cohort of younger UK adults who were obese or overweight with at least one additional risk factor for the development of Type 2 DM.

\section{METHODS}

\section{Study population and recruitment}

In 2011, 193 young adults aged 18-40 years were recruited from across Leicestershire and Northamptonshire, UK as part of Project STAND, a 2-arm parallel group randomised controlled trial. The methodology for this trial has 
been described in detail elsewhere [12]. The study was granted ethical approval by the local Research Ethics Committee. Informed verbal and written consent was obtained from all participants. Inclusion criteria were age 18-40 years with a BMI in the obese $\left(\geq 30 \mathrm{~kg} / \mathrm{m}^{2} ; \geq 27.5 \mathrm{~kg} / \mathrm{m}^{2}\right.$ for South Asians) or overweight range $\left(\geq 25 \mathrm{~kg} / \mathrm{m}^{2} ; \geq 23 \mathrm{~kg} / \mathrm{m}^{2}\right.$ for South Asians) plus an additional risk factor for Type 2 DM (family history of diabetes or cardiovascular disease in a first degree relative; previous gestational diabetes; polycystic ovarian syndrome). Exclusion criteria included significant illness, steroid use, preexisting diabetes (self reported or recorded on GP database), pregnancy or an inability to communicate in English. Recruitment was co-ordinated via the East Midlands and South Yorkshire Primary Care Research Network. An electronic general practice (GP) database search was conducted to identify participants who met the inclusion criteria. Invitations were sent by the GP to the participants who then replied directly to the study team.

\section{Study measures}

Nurse administered questionnaires were used to assess medical history, drug and family history, smoking status and ethnicity. Arterial blood pressure was measured in the sitting position (Omron, Healthcare, Henfield, UK); three measurements were obtained and the average of the last two measurements used. Hypertension was defined as a systolic blood pressure $\geq 140$ or diastolic $\geq 90 \mathrm{mmHg}$ or treatment for hypertension [13]. Other measures included body weight and body fat percentage (Tanita BC 420SMA, Tanita, West Drayton, UK), waist circumference (midpoint between the lower costal margin and iliac crest), and height to the nearest $0.1 \mathrm{~kg}, 0.5 \%$ and $0.5 \mathrm{~cm}$ respectively.

\section{Glycaemia}

Participants were invited to attend a baseline measurement session after a 12-hour fast and 24 hours of avoiding vigorous intensity exercise. Individuals underwent a standardized $75 \mathrm{~g}$ OGTT and an HbA1c to measure glycaemia. $\mathrm{HbA1c}$ was interpreted according to the 2011 WHO criteria (HbA1c $\geq 48 \mathrm{mmol} / \mathrm{mol}(6.5 \%)$ diabetes; $42-46 \mathrm{mmol} / \mathrm{mol}$ (6.0-6.4\%) "high risk") [14, 15]. The OGTT results were interpreted according to the $1999 \mathrm{WHO}$ criteria and divided into diabetes, isolated impaired fasting glycaemia (IFG), isolated impaired glucose tolerance (IGT) or impaired glucose regulation (IGR) (both IFG and IGT) [16]. In this study, diabetes is defined by an OGTT and/or $\mathrm{HbA} 1 \mathrm{c}$ result in the diabetes range. Impaired glucose metabolism (IGM) refers to any previously undiagnosed glucose abnormality including an $\mathrm{HbA} 1 \mathrm{c} \geq 42 \mathrm{mmol} / / \mathrm{l}$ (6\%) and/or OGTT defined IFG, IGT or Type 2 DM.

\section{Laboratory analysis}

Serum total cholesterol, HDL cholesterol, and triglycerides; liver function, urea and creatinine and 25-hydroxyvitamin D were measured. Low density lipoprotein cholesterol (LDL) was estimated using the Friedewald equation [17]. Dyslipidaemia was defined as lipid lowering treatment or triglycerides $\geq 1.7 \mathrm{mmol} / \mathrm{l}$ or $\mathrm{HDL}<1.03$ (males) and $<1.29 \mathrm{mmol} / \mathrm{l}$ (females) [18]. Plasma glucose, lipids and liver function tests were all measured using standard enzymatic endpoint methods on an ADVIA Chemistry System (Bayer Healthcare, NY, USA). An abnormal ALT was defined as $>53 \mathrm{iU} / \mathrm{L}$. HbA1c was measured by ion exchange liquid chromatography (G7; Tosoh, Tokyo, Japan). 
25-Hydroxyvitamin D (25(OH)D) was quantified using liquid chromatography mass spectrometry (6410 Triple Quad, Agilent Technologies UK Ltd, Wokingham, UK).

\section{Statistical methods}

Normality was assessed using the Kolmogorov-Smirnov test, histograms and normal Q-Q plot. Continuous data were expressed as mean (standard deviation (SD)) if they were normally distributed. Non-parametric continuous variables were expressed as median $(25 \%$ and $75 \%$ interquartile range (IQR)). Categorical data were expressed as a percentage. Chi square was used to compare categorical variables between two groups. Statistical tests were performed using SPSS 18.0 software (Statistical Package for the Social Sciences, Chicago, IL). $p<0.05$ was considered statistically significant.

\section{RESULTS}

193 participants who completed the STAND study baseline visit were included. $68 \%(n=131)$ were female. $21 \%(n=40)$ were of BME origin (Asian $\mathrm{n}=23$; Black $\mathrm{n}=10$; mixed ethnic origin $\mathrm{n}=7$ ). Median (+/-interquartile range) age and BMI were 33.8 (29.3-37.9) years and $33.9(31.2-37.6) \mathrm{kg} / \mathrm{m}^{2}$ respectively. $43 \%$ had a first degree family history of Type 2 DM. Baseline anthropometric and laboratory data are described in Table 1.

\section{Prevalence of impaired glucose metabolism}

Diabetes was present in $4.7 \%(n=9)$ of the study population. IGM was present in $18.1 \%(n=35)$. Of those with IGM, $4.7 \%(n=9)$ had an $\mathrm{HbA} 1 \mathrm{c} \geq 48 \mathrm{mmol} / \mathrm{mol}$ (6.5\%)); 9.3\% ( $n=18)$ HbA1c 42-46mmol/mol (6.0-6.4\%); 3.1\% ( $n=6)$ Type 2 DM on OGTT; $6.2 \%(n=12)$ isolated IGT; $2.1 \%(n=4)$ isolated IFG; $1 \%(n=2)$ both IFG and IGT. 32.5\% $(n=13)$ of the BME population had IGM compared to $14.5 \%(n=22)$ of the White Caucasian population $(p=0.01) .15 .3 \%(n=20)$ of females had IGM compared to $24.2 \%(n=15)$ males $(p=0.13)$. All participants aged $<25$ years $(n=22)$ had normal glucose status.

\section{Cardiometabolic risk}

$58.5 \%(n=113)$ had dyslipidaemia and $28.0 \%(n=54)$ had hypertension. $0.5 \%$ $(n=1)$ and $4.7 \%(n=9)$ were prescribed lipid lowering and anti-hypertensive therapy respectively. $7.3 \%(n=14)$ had an elevated alanine transferase, a marker of possible fatty liver disease. 31.1\% $(n=60)$ were vitamin $D$ deficient $(<30 \mathrm{nmol} / \mathrm{l})$.

\section{CONCLUSIONS}

Screening young overweight and obese adults for Type 2 DM successfully identified diabetes (4.7\%) and impaired glucose metabolism (18.1\%). The diabetes yield in this cohort was similar to other larger screening studies in older UK populations and adds further support to the recent national recommendation to screen those aged 25-39 years for diabetes [11].

The ADDITION-Leicester population based diabetes screening study, with a mean age 57 years, identified 3.3\% of the population with undiagnosed Type 2 DM [19]. These data were based on OGTT results and are comparable with 
the OGTT diabetes yield (3.1\%) in the younger high risk STAND cohort. Similar figures have been reported in other UK studies in overweight and obese populations $>40$ years, with reported yields between $1.4 \%$ and $5.4 \%$ $[20,21]$. However, it is important to highlight that the STAND cohort were a high risk group and not representative of the general Leicester population. In Leicester $23 \%$ of the population are obese and 36\% of BME origin compared to $89 \%$ and $21 \%$ of the STAND study population respectively $[22,23]$. The BME populations were underrepresented in this study, a group which typically has more than double the prevalence of screen detected diabetes [19]. These factors limit the generalisability of our findings. Nonetheless, the yield obtained highlights that undetected Type $2 \mathrm{DM}$ is prevalent in high risk young cohorts and is worth pursuing. Furthermore, NICE recommend targeted screening towards minority ethnic groups, a recommendation supported by our finding of significantly more IGM in the BME group. However, the prevalence of IGM (14.5\%) and Type 2 DM (2\%) in the White Caucasian population was still considerable. The increasing prevalence of abnormal glucose metabolism in younger White Caucasian adults is recognised and requires further exploration in larger studies [24].

The prevalence of IGM in this younger population has implications for clinical practice. Type $2 \mathrm{DM}$ in younger people represents an aggressive phenotype with multiple co-morbidities (hyperlipidaemia, non alcoholic fatty liver disease, morbid obesity) and the rapid development of complications such as nephropathy and hypertension, often more quickly than people with Type 1 DM and despite relatively tight glycaemic control [2]. Early detection of Type 2 DM in this group is paramount in order to prevent the development of irreversible complications during their working lives. This is particularly important in young women of child bearing age. If a woman with undiagnosed Type 2 DM becomes pregnant, there is substantial risk to the unborn foetus, particularly during organogenesis in the first trimester when congenital defects occur in the presence of uncontrolled hyperglycaemia [25]. Such risks can be minimised by tight glycaemic control and high dose folic acid in early pregnancy [25]. In view of the high rates of IGM in our young cohort, it would seem sensible to consider diabetes screening in obese women and overweight women with a family history of diabetes or cardiovascular disease. The main strengths of this study are the unique insights into the prevalence of dysglycaemia and cardiovascular risk factors in a younger high risk UK population. However, interpretation of the data requires some caution given the sample size, small in comparison to large diabetes screening studies. Also, these participants were motivated subjects who volunteered for inclusion in a randomised controlled behavioural intervention trial on the basis of being 'at risk', and this may limit how generalisable the findings are. However, few data are available on the prevalence of impaired glucose metabolism in this group so the findings of this study fill a gap in current knowledge.

In conclusion, screening for Type $2 \mathrm{DM}$ in a high risk multi-ethnic population of younger adults successfully identifies Type 2 DM and IGM. The findings will need confirmation in larger populations. 


\section{Acknowledgements and funding}

This study is part of the research portfolio supported by the NIHR LeicesterLoughborough Diet, Lifestyle and Physical Activity Biomedical Research Unit at the University Hospitals of Leicester NHS Trust, University of Leicester and Loughborough University and the NIHR Collaboration for Leadership in Applied Health Research and Care - Leicestershire, Northamptonshire and Rutland (NIHR CLAHRC for LNR). The views expressed are those of the author(s) and not necessarily those of the NHS, the NIHR or the Department of Health.

We would like to acknowledge the following people who have collected data or contributed to the running of the study:

Jeanette Barnett, Paul Bray, Jane Brela, Lesley Bryant, Heather Daly, Jayne Hill, Janet Jarvis, Hamidreza Mani, Champa Merry, Mo Radia, Jason Rigby, Lorraine Martin Stacey, Vaithehy Shanmugam, Martina Sharman, Jacqui Troughton, Sian Williams.

The STAND study is a MRC (NPRI) funded study (Project \#91409). The funder has not had any role in data collection, analysis or manuscript preparation.

\section{Competing interests}

The authors declare that they have no competing interests.

\section{Authors contributions}

The original study proposal ideas were led by SJHB, MD, TG, KK, MN, and TY. EW and CE participated in the design, management and coordination of the study. EW, CE, TY and JH collected and analysed data. EW wrote the first draft of the manuscript. All have been involved in revising the content of the manuscript. All authors have read and approved the final manuscript. 


\section{REFERENCES}

1. Wilmot EG, Davies MJ, Yates T, Benhalima K, Lawrence IG, Khunti K. Type 2 diabetes in younger adults: the emerging UK epidemic. Postgrad Med J. 2010; 86:711-8.

2. Eppens MC, Craig ME, Cusumano J, Hing S, Chan AK, Howard NJ, et al. Prevalence of diabetes complications in adolescents with Type 2 compared with Type 1 diabetes. Diabetes Care 2006; 29:1300-6.

3. Zdravkovic V, Daneman D, Hamilton J. Presentation and course of Type 2 diabetes in youth in a large multi-ethnic city. Diabet Med 2004; 21:1144-8.

4. Upchurch SL, Brosnan CA, Meininger JC, Wright DE, Campbell JA, McKay SV, et al. Characteristics of 98 children and adolescents diagnosed with Type 2 diabetes by their health care provider at initial presentation. Diabetes Care 2003;26:2209.

5. Hillier TA, Pedula KL. Complications in young adults with early-onset Type 2 diabetes: Losing the relative protection of youth. Diabetes Care 2003;26:2999-3005.

6. Feldstein AE, Charatcharoenwitthaya $P$, Treeprasertsuk S, Benson JT, Enders FB, Angulo P. The natural history of non-alcoholic fatty liver disease in children: A follow-up study for up to 20 years. Gut 2009; 58:1538-44.

7. Abdullah A, Wolfe R, Stoelwinder JU, de Courten M, Stevenson C, Walls $\mathrm{HL}$, et al. The number of years lived with obesity and the risk of all-cause and cause-specific mortality. Int J Epidemiol 2011; 40:985-96.

8. Holman RR, Paul SK, Bethel MA, Matthews DR, Neil HA. 10-year follow-up of intensive glucose control in Type 2 diabetes. N Engl J Med 2008;

359:1577-89.

9. Yates T, Khunti K, Bull F, Gorely T, Davies MJ. The role of physical activity in the management of impaired glucose tolerance: A systematic review. Diabetologia 2007; 50:1116-26.

10. Carter P, Gray LJ, Troughton J, Khunti K, Davies MJ. Fruit and vegetable intake and incidence of Type 2 diabetes mellitus: Systematic review and meta-analysis. BMJ 2010; 341:c4229.

11. National Institute for Health and Clinical Excellence. Preventing Type 2 diabetes: risk identification and interventions for individuals at high risk. London: NICE 2012.

12. Wilmot EG, Davies MJ, Edwardson CL, Gorely T, Khunti K, Nimmo M, et al. Rationale and study design for a randomised controlled trial to reduce sedentary time in adults at risk of Type 2 diabetes mellitus: Project STAND (sedentary time ANd diabetes). BMC Public Health 2011; 11:908

13. Mancia G, De Backer G, Dominiczak A et al. (September 2007). "2007 ESH-ESC Practice Guidelines for the Management of Arterial Hypertension: ESH-ESC Task Force on the Management of Arterial Hypertension". J. Hypertens 2007; 25: 1751-62.

14. World Health Organisation. Use of Glycated Haemoglobin $(\mathrm{HbA1c})$ in the Diagnosis of Diabetes Mellitus. 2011. Available at:

http://www.who.int/diabetes/publications/report-hba1c 2011.pdf Last accessed 5 December 2012.

15. National Health Service Health Check. Vascular Risk Assessment and Management Best Practice Guidance. .April 2009; 9: 19-24. Available at: http://www.dh.gov.uk/prod_consum_dh/groups/dh_digitalassets/documents/ 
ditalasset/dh_098410.pdf

16. Alberti $K \bar{G}$, Zimmet $P Z$. Definition, diagnosis and classification of diabetes mellitus and its complications. Part 1: diagnosis and classification of diabetes mellitus provisional report of a WHO consultation. Diabet Med 1998; 15: 539_ 553.

17. Friedewald WT, Levy RI, Fredrickson DS. Estimation of the concentration of low-density lipoprotein cholesterol in plasma, without use of the preparative ultracentrifuge. Clin Chem 1972; 18:499-502.

18. Alberti KG, Zimmet P, Shaw J, IDF Epidemiology Task Force Consensus Group. The metabolic syndrome--a new worldwide definition. Lancet 2005; 366:1059-62.

19. Webb DR, Gray LJ, Khunti K, Srinivasan B, Taub N, Campbell S, et al. Screening for diabetes using an oral glucose tolerance test within a western multi-ethnic population identifies modifiable cardiovascular risk: The ADDITION-leicester study. Diabetologia 2011; 54:2237-46.

20. Goyder E, Wild S, Fischbacher C, Carlisle J, Peters J. Evaluating the impact of a national pilot screening programme for Type 2 diabetes in deprived areas of england. Fam Pract 2008; 25:370-5.

21. Greaves CJ, Stead JW, Hattersley AT, Ewings P, Brown P, Evans PH. A simple pragmatic system for detecting new cases of Type 2 diabetes and impaired fasting glycaemia in primary care. Fam Pract 2004; 21:57-62.

22. South East Public Health Observatory. Cardiovascular disease PCT health profile: Leicester City. 2012. Available at:

http://www.sepho.org.uk/NationalCVD/docs/5PC CVD\%20Profile.pdf Last accessed 5 December 2012.

23. National Health Service Leicester City and Leicester City Council Joint Strategic Needs Assessment. 2008. Available at:

http://www.leicestercity.nhs.uk/Library/paper d jsna substantive draft.pdf Last accessed 5 December 2012.

24. Wiegand $S$, Maikowski $U$, Blankenstein $O$, Biebermann $H$, Tarnow $P$, Gruters A. Type 2 diabetes and impaired glucose tolerance in european children and adolescents with obesity -- a problem that is no longer restricted to minority groups. Eur J Endocrinol 2004; 151:199-206.

25. Confidential enquiry into maternal and child health (CEMACH). Diabetes in pregnancy: are we providing the best care? Findings of a national enquiry. England, Wales and Northern Ireland. London: CEMACH, 2007. 
Table 1. Anthropometric and laboratory outcomes

\begin{tabular}{|c|c|c|c|}
\hline Descriptive (n=187-193) & $n=$ & Median/\% (IQR) & $95 \% \mathrm{Cl}$ \\
\hline Age (years) & 193 & $33.8(29.3-37.9)$ & 32.1-33.7 \\
\hline Gender (\% female) & 193 & 67.9 & \\
\hline Ethnicity (\% BME) & 193 & 20.7 & \\
\hline Systolic BP (mmHg) & 193 & $119(112-129)$ & 119.1-123.2 \\
\hline Diastolic BP (mmHg) & 193 & $83(78-89)$ & $82.7-85.5$ \\
\hline $\mathrm{BMI}\left(\mathrm{kg} / \mathrm{m}^{2}\right)$ & 193 & $33.9(31.2-37.6)$ & $33.9-35.3$ \\
\hline Obese (\%) & 193 & 88.6 & \\
\hline Waist $(\mathrm{cm})$ & 193 & $101(94-111)$ & $102-105$ \\
\hline Waist Hip Ratio & 193 & $0.88(0.81-0.95)$ & $0.87-0.90$ \\
\hline Body fat (\%) & 193 & $41.9(35.2-46.2)$ & $39.6-41.6$ \\
\hline Fat free mass (\%) & 193 & $53.9(49.4-66.3)$ & $55.7-59.4$ \\
\hline Cholesterol $(\mathrm{mmol} / \mathrm{l})$ & 192 & $4.8(4.2-4.8)$ & $4.8-5.1$ \\
\hline $\mathrm{LDL}(\mathrm{mmol} / \mathrm{l})$ & 188 & $3.0(2.4-3.4)$ & $2.9-3.1$ \\
\hline $\mathrm{HDL}(\mathrm{mmol} / \mathrm{l})$ & 191 & $1.2(1.0-1.4)$ & $1.2-1.3$ \\
\hline $\operatorname{Trig}(\mathrm{mmol} / \mathrm{l})$ & 192 & $1.3(0.9-1.9)$ & $1.4-1.8$ \\
\hline $\mathrm{HbA1c}(\mathrm{mmol} / \mathrm{mol})$ & 191 & $46(36-40)$ & $38-39$ \\
\hline HbA1c (\%) & 191 & $5.6(5.4-5.8)$ & $5.6-5.7$ \\
\hline Fasting glucose $(\mathrm{mmol} / \mathrm{l})$ & 192 & $4.8(4.5-5.1)$ & $4.8-5.2$ \\
\hline 2 hour glucose $(\mathrm{mmol} / \mathrm{l})$ & 192 & $5.2(4.3-6.4)$ & $5.3-6.1$ \\
\hline ALT (iu/l) & 192 & $23(17.34)$ & $26.0-31.2$ \\
\hline AST (iu/l) & 187 & $22(18-29)$ & $23.2-25.7$ \\
\hline Vitamin D <30nmol/l (\%) & 190 & 31.1 & \\
\hline
\end{tabular}

Results presented as median (interquartile range (IQR)) or percentage (\%). BME = black or minority ethnic group. 